\title{
ESFENÓFITAS DA FORMAÇAO RIO BONITO (PERMIANO INFERIOR) NA REGIÃO DE TAIÓ, SANTA CATARINA, BRASIL
}

\author{
DAIANA ROCKENBACH BOARDMAN \\ Programa de Pós-graduação em Geociências, Instituto de Geociências, UFRGS, Cx.P. 15001, 91501-970, Porto Alegre, \\ RS, Brasil.daiana.boardman@gmail.com \\ ROBERTO IANNUZZI \\ Departamento de Paleontologia e Estratigrafia, Instituto de Geociências, UFRGS, Cx.P. 15001, 91501-970, \\ Porto Alegre, RS, Brasil.roberto.iannuzzi@ufrgs.br
}

TÂNIA LINDNER DUTRA

Programa de Pós-Graduação em Geologia, UNISINOS, Av. Unisinos, 950, 93022-000, São Leopoldo, RS, Brasil. tdutra@unisinos.com.br

\begin{abstract}
RESUMO - O presente trabalho apresenta a descrição dos primeiros achados de restos vegetais fósseis no Município de Taió, Santa Catarina, Brasil, representados por restos de Sphenopsida. Esta macroflora foi identificada em rochas correspondentes à porção basal da Formação Rio Bonito, Permiano Inferior da bacia do Paraná. O material paleobotânico aqui descrito é composto de espécimes de Phyllotheca australis e Paracalamites australis, provenientes de área situada próxima à margem esquerda do rio Taió. $\mathrm{O}$ achado de restos vegetais, em níveis inferiores àqueles onde ocorre a reconhecida macrofauna marinha denominada 'Assembléia Taió', amplia o registro fossilífero da região e auxilia no entendimento da sucessão pós-glacial desta porção da bacia do Paraná.
\end{abstract}

Palavras-chave: Phyllotheca australis, Paracalamites australis, Formação Rio Bonito, bacia do Paraná, Santa Catarina.

ABSTRACT - SPHENOPSIDS FROM THE RIO BONITO FORMATION (LOWER PERMIAN) IN THE TAIÓ REGION, SANTA CATARINA STATE, BRAZIL. This paper records the first fossil plants from the Taió Municipality (Santa Catarina State, Brazil), represented by remains of Sphenopsida. This macrofloral record was identified in outcrops corresponding to the basal portion of the Rio Bonito Formation (Lower Permian of the Paraná Basin). The studied material is made up of specimens of Phyllotheca australis and Paracalamites australis, which were collected near the left margin of Taió River. The beds containing this macroflora are overlaid by deposits with the well-known marine macrofauna named 'Taió Assemblage' extending the fossil record of the region and contributing to a better understanding of the postglacial succession of this portion of the Paraná Basin.

Key words: Phyllotheca australis, Paracalamites australis, Rio Bonito Formation, Paraná Basin, Santa Catarina State.

\section{INTRODUÇÃO}

Em termos paleobotânicos, o Estado de Santa Catarina possui um rico e significativo acervo, que vem sendo pesquisado desde os estudos pioneiros de White (1908), passando por Read (1941), Dolianiti (1946, 1948, 1953a-c, 1954a,b, 1956a,b), Bernardes-de-Oliveira $(1969,1977,1978$, 1980, 1981, 1988), Rigby (1972a,b) e Bortoluzzi (1975), entre outros. A abundância de trabalhos em paleobotânica no estado decorre do grande interesse comercial nos depósitos de carvão que afloram na borda leste da bacia do Paraná.

Em nível paleontológico, o município de Taió (Figura 1) é conhecido, até o presente momento, por suas excelentes exposições de depósitos marinhos com faunas de moluscos bivalves, representativos de uma sucessão pós-glacial registrada no Membro Paraguaçu, porção média da Formação Rio Bonito. Esta macrofauna vem sendo bastante estudada desde a década de 1930, a partirda descoberta de conchas fósseis de origem marinha (Oliveira, 1930). Posteriormente, a associação de invertebrados marinhos de Taió foi estudada, sucessivamente, por uma série de pesquisadores: Reed (1930, 1935), Kegel \& Costa (1951), Beurlen (1954, 1957), RochaCampos $(1964,1967,1970)$ e Rocha-Campos \& Simões (1993). Rocha-Campos (1964), por sua vez, cunhou o termo 'Assembléia Taió' para designar a fauna constituída por moluscos pectinídeos (Pelecipoda), gastrópodes (Gastropoda) e equinodermas (Asteroidea, Echinoidea e Ophiuroidea).

Em termos de vegetais fósseis, Rocha-Campos coletou em 1959 material referente à esfenófitas, depositado na coleção de entrada do Instituto de Geociênciasda USP. RochaCampos (1964:12), no volume de sua tese, apenas cita o achado de restos de Sphenophyta (Calamitales?) no afloramento do Clube Caça e Tiro, pertencente à metade inferior da Formação Rio Bonito, os quais permaneceram, desde então, inéditos. 


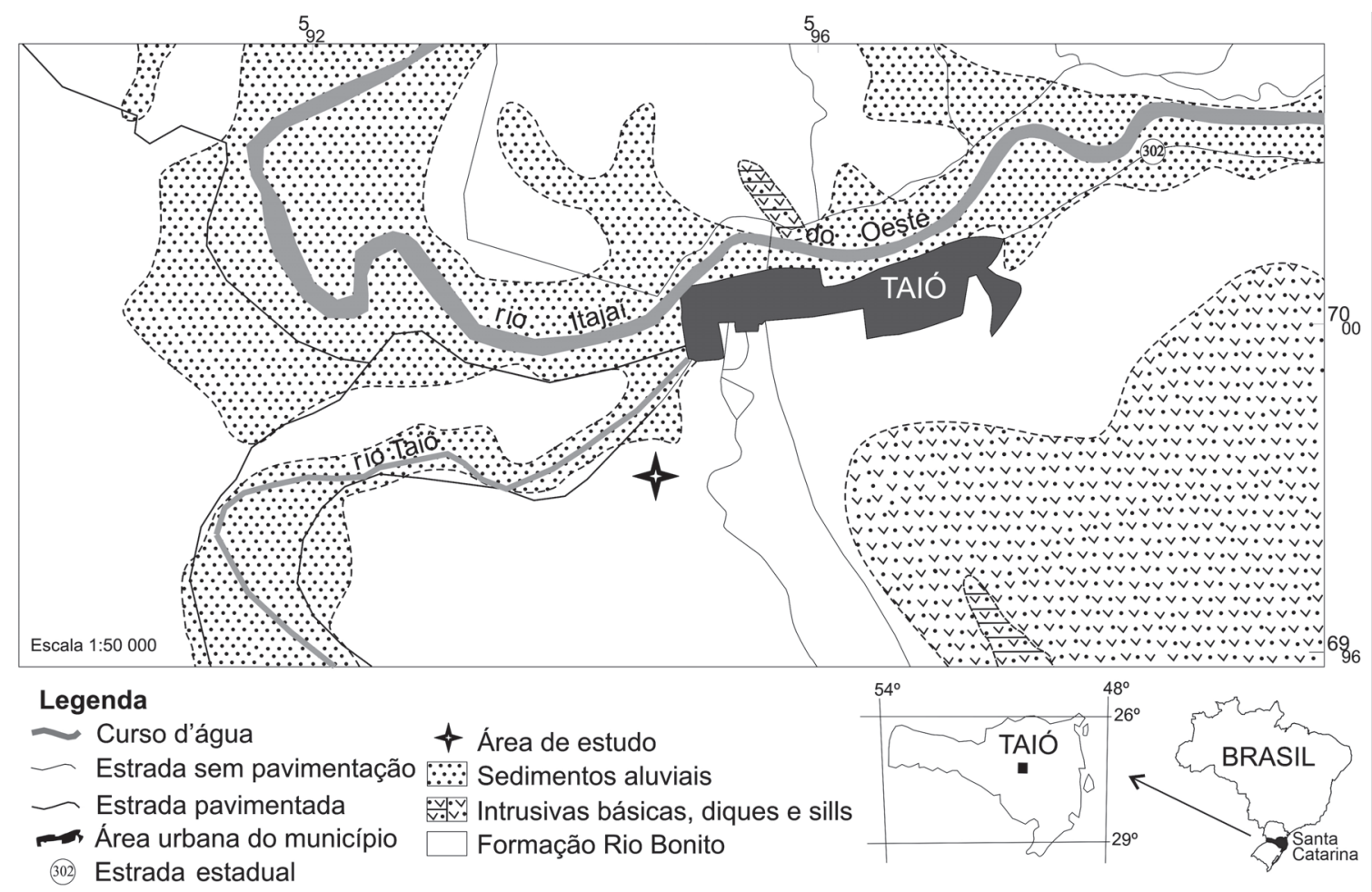

Figura 1. Mapa de localização da área de estudo, Clube Caça e Tiro, município de Taió (adaptado de Boardman, 2006). Dados geológicos baseados em Rocha-Campos (1964).

Figure 1. Location map of the study area, Caça e Tiro Club, in the Taió town (adapted from Boardman, 2006). Geological data based on Rocha-Campos (1964).

Em trabalhos de campo desenvolvidos como parte dos projetos coordenados pelos autores (RI, TLD), coletaram-se abundantes restos vegetais num único sítio no município de Taió (afloramento Bruno Peiker), em níveis inferiores à camada que contém os moluscos da 'Assembléia Taió', os quais foram preliminarmente relatados por Boardman et al. $(2005,2006)$.

$\mathrm{O}$ material aqui estudado corresponde àquele coletado por Rocha-Campos em 1959 e que foi parte integrante da dissertação de mestrado de Boardman (2006). Esta contribuição representa o primeiro estudo sistemático dos restos vegetais do município de Taió.

\section{GEOLOGIA}

Na década de 1960, Rocha-Campos (1964, 1967, 1970) desenvolveu minuciosos trabalhos sobre a macrofauna fóssil da região de Taió. Em sua tese, Rocha-Campos (1964) realizou uma investigação estratigráfica e paleontológica na área em que resultou, em parte, na confecção de um mapa geológico detalhado da região na escala 1:27.000. Este mapeamento mostrou que a região é constituída por sedimentos dos grupos Tubarão (Sub-Grupo Itararé e Formação Rio Bonito) e Passa Dois (Formações Palermo e Irati), e posicionou o único horizonte marinho fossilífero por ele encontrado, representado por alguns decímetros de arenito fino, na parte médio-superior da Formação Rio Bonito. Ao longo daquele trabalho, os restos vegetais atribuídos a Sphenophyta, encontrados no terreno do Clube Caça e Tiro, foram posicionados estratigraficamente na porção basal da
Formação Rio Bonito. As porções basal e média desta formação foram denominadas, mais tarde, de membros Triunfo e Paraguaçu, respectivamente (Schneider et al., 1974).

Krebs \& Menezes Filho (1984) realizaram amplo mapeamento geológico que enfocou as camadas de carvão da região de Taió e Rio do Sul, mas do qual não resultou nenhuma contribuição paleontológica. Naquele mapeamento, no entanto, os sedimentos aflorantes nas áreas em torno do município de Taió foram determinados como pertencendo ao Membro Paraguaçu, porção média da Formação Rio Bonito, levando Boardman (2006) e Boardman et al. (2006) a posicionarem os vegetais fósseis da região na porção média da Formação Rio Bonito.

Com base nas informações fornecidas por Rocha-Campos (1964) e no perfil estratigráfico obtido das seções aflorantes na área do Clube Caça e Tiro (Figura 2), sugere-se o provável posicionamento estratigráfico do material aqui estudado junto ao intervalo composto pelos arenitos finos, que são encontrados na porção mais basal da Formação Rio Bonito.

Quanto à idade dos depósitos, inicialmente Oliveira (1930) sugeriu uma vinculação da associação fóssil da região de Taió com os macrofósseis marinhos de New South Wales, Austrália, datados como sendo do Eopermiano. Posteriormente, Rocha-Campos $(1964,1970)$ afirmou que o caráter endêmico da associação de Taió não permitia uma correlação segura com outras bacias nacionais ou mesmo gonduânicas, invalidando a relação com as faunas australianas sugerida por Oliveira (1930). No entanto, Runneger (1972) e Dickins (1963) citaram a possível presença 
do táxon Heteropecten catharinae (Reed, 1930) na Formação Mingenew e a sua ocorrência na porção inferior do Grupo Lyons, no oeste da Austrália. Com base nisto, Rocha-Campos \& Rösler (1978) sugeriram uma possível idade Artinskiana, a mesma atribuída às faunas australianas que continham a espécie brasileira, para a 'Assembléia de Taió'. Rocha-Campos \& Simões (1993) ampliaram a lista de taxa da associação de Taió, descrevendo a espécie Australomya sinuosa, onde reiteram a idade Artinskiana já sugerida.

\section{MATERIAL E MÉTODOS}

O material estudado provém do município de Taió, região centro-oeste de Santa Catarina, e corresponde às amostras citadas por Rocha Campos (1964) da área do Clube Caça e Tiro, situada próxima à margem esquerda do rio Taió (Figuras 1,2). Este material inclui três amostras (GP/3T 2434, 2435, 2436), constituídas de várias partes e contra-partes que são indicadas por letras minúsculas inseridas junto ao número das amostras (GP/3T 2434a-g; 2435a, b; 2436a, b) e que, provavelmente, correspondem, originalmente, a partes de um único bloco. Em algumas amostras foram analisados mais de um exemplar que está representado por uma letra maiúscula inserida após numeração da amostra (GP/3T 2434aA; GP/3T 2434aB). Os espécimes estão preservados na forma de impressões e representam fragmentos de caules, ramos e verticilos foliares de Sphenopsida.

O estudo taxonômico deu-se pela observação a olho nu e com microscópio estereoscópio (Wild, Modelo M5-86360) e fotografias digitais, a partir dos quais foram realizadas medições com paquímetro e descrições. Previamente, foi realizado um levantamento bibliográfico das características utilizadas por diferentes autores (Rigby, 1966, 1969; Millan, 1977; Rohn \& Lages, 2000; Zampirolli \& Bernardes-deOliveira, 2000) para a descrição de cada parte vegetal, a fim de facilitar a comparação dos espécimes estudados com aqueles descritos na literatura. Foram selecionadas as seguintes características, de acordo com as respectivas partes do vegetal: (i) caules articulados: dimensões e razão largura/comprimento dos entrenós; quantidade de costelas por entrenó, distância entre si e razão do número de costelas por centímetro; ângulo de inserção dos ramos (secundários) foliares (Tabela 1); (ii) ramos foliares: dimensões, razão largura/comprimento dos entrenós; ângulo de inserção dos folíolos nos ramos; morfologia, ângulo de saída e quantidade de folíolos por verticilo; distância dos verticilos foliares entre si (Tabela 2). Quando não foi possível a obtenção do número exato de folíolos por verticilo, realizouse uma inferência do número total com base na área ocupada por cada folíolo, que se encontra indicada ao longo do trabalho. A sistemática supragenérica segue Stewart \& Rothwell (1993).

Os espécimes aqui analisados, cedidos por empréstimo ao Instituto de Geociências da Universidade Federal do Rio Grande do Sul, estão catalogados sob a sigla GP 3T e depositados no Departamento de Geologia Sedimentar e Ambiental do Instituto de Geociências da Universidade de São Paulo.

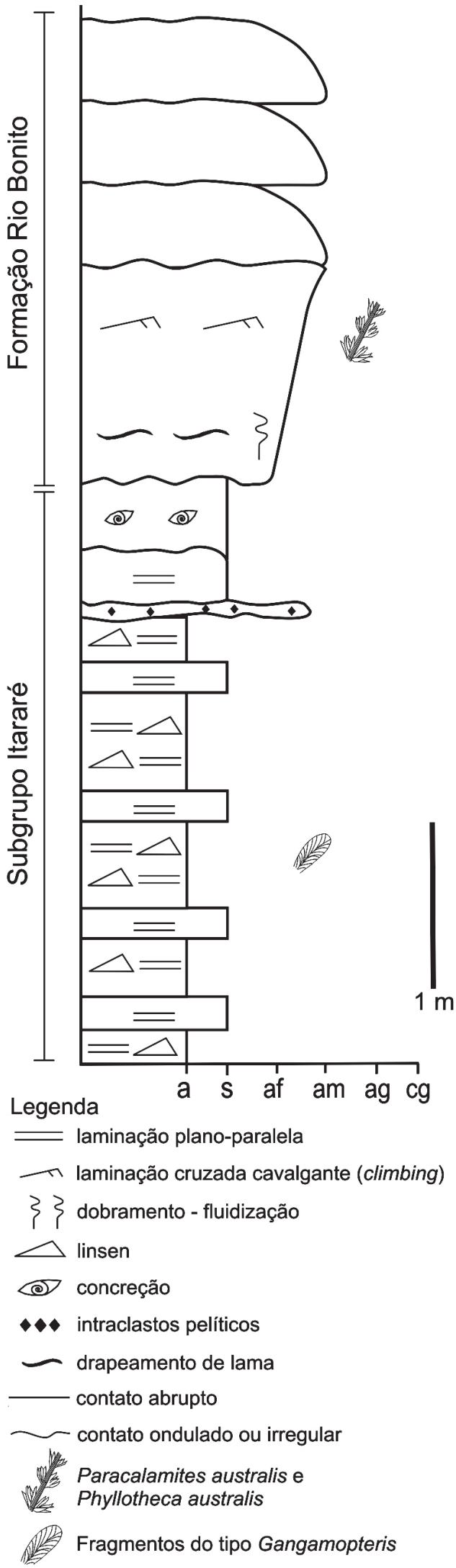

Figura 2. Perfil estratigráfico da seção da área do Clube Caça e Tiro (modificado de Boardman, 2006), com a possível posição das amostras estudadas baseado em Rocha-Campos (1964).

Figure 2. Stratigraphic section from the area of the Caça e Tiro Club (modified from Boardman, 2006), with the probable position of studied samples based on Rocha-Campos (1964). 


\section{SISTEMÁTICA}

\section{Divisão TRACHEOPHYTA \\ Classe SPHENOPSIDA \\ OrdemEQUISETALES \\ Família Incertae sedis}

Gênero Paracalamites Zalessky, 1927

\section{Paracalamites australis Rigby, 1966}

Material estudado. GP/3T 2434a,b (Figura 3).

Localidade. Afloramento Clube Caça e Tiro (Rocha-Campos, 1964; Boardman, 2006), próximo à margem esquerda do rio Taió, município de Taió, Santa Catarina, Brasil.

Descrição. O material é composto por cinco fragmentos de caules articulados, com nós e entrenós, sem folhas ou estruturas reprodutivas conectadas, sendo que dois deles (GP/3T 2434a; Figura 3A) apresentam ramificações (Tabela 1). Os espécimes estão preservados sob a forma de moldes caulinares externos e incluem caules de dois portes distintos: caules principais, mais basais, de maior calibre e medidas mais homogêneas, e caules apicais com ramificações.

Os fragmentos de caules possuem comprimento de até
$245 \mathrm{~mm}$, chegando a apresentar 11 regiões nodais preservadas. Nos caules principais (GP/3T 2434aC, D; GP/3T $2434 \mathrm{bH}$ ), a largura varia de $25-35 \mathrm{~mm}$ e o comprimento do entrenó é relativamente constante entre os diferentes espécimes, variando de 31,6-39,3 mm, o que mantém a razão largura/comprimento dos entrenós entre 1:1 e 1:1,8 (Figura 3A, espécimes C, D; Figura 3B). A quantidade de costelas (feixes vasculares) também se mantém constante, variando de 16 a 20 costelas, na superfície visível, ao longo do caule, com densidade de 6 a 8 costelas $/ \mathrm{cm}$. Os feixes vasculares são opostos, ultrapassando a região nodal. Nos caules apicais $(\mathrm{GP} / 3 \mathrm{~T} 2434 \mathrm{aA}, \mathrm{B})$ a largura dos entrenós varia entre 9,5-21 $\mathrm{mm}$ no decorrer do caule, com o comprimento variando de 16,7-27,2 mm na região mais proximal, e entre 7,7-19,6 mm na extremidade mais distal (Figura 3A, espécimes A, B). A razão largura/comprimento dos entrenós é bastante variada, oscilando entre 1:0,6 e 1:0,9 nas extremidades mais distais, onde estão os entrenós com ramificações, e entre 1:1,2 a 1:1,7, nas regiões mais proximais. O número de costelas também muda da região proximal do caule, com 13 a 15 costelas, para a região mais distal, com apenas 8 costelas na superfície visível. No entanto, ambas as regiões apresentam cerca de 6 a 9 costelas $/ \mathrm{cm}$. Em geral, as costelas são opostas e

Tabela 1. Medidas (em $\mathrm{mm}$ ) dos caules e ramos dos espécimes. Abreviaturas: E, entrenós; L, largura; C, comprimento; L/C, razão largura/comprimento; N, regiões nodais; $\mathbf{A}$, ângulos de inserção dos ramos foliares; INC, incompleto.

Table 1. Measurements (in $\mathrm{mm}$ ) from the stems and leafless shoots of the specimens. Abbreviations: $\mathbf{E}$, internodes; L, width; C, length; L/C, width/length ratio; $\mathbf{N}$, nodal regions; $\mathbf{A}$, angles of insertion of the leaf shoots; INC, incomplete.

\begin{tabular}{|c|c|c|c|c|c|c|c|c|c|}
\hline \multirow{2}{*}{ Espécime } & \multirow{2}{*}{$\begin{array}{c}\text { Comprimento } \\
\text { total }\end{array}$} & \multicolumn{4}{|c|}{ Entrenós } & \multirow{2}{*}{$\begin{array}{l}\mathrm{N}^{\circ} \text { de } \\
\text { costelas }\end{array}$} & \multirow{2}{*}{$\begin{array}{l}\text { Costelas } \\
\text { por } \mathrm{cm}\end{array}$} & \multirow{2}{*}{$\begin{array}{l}\text { Distância entre } \\
\text { costelas }\end{array}$} & \multirow{2}{*}{$\frac{\text { Ramos }}{N}$} \\
\hline & & $E$ & $\mathrm{~L}$ & $C$ & $\mathrm{~L} / \mathrm{C}$ & & & & \\
\hline \multirow{9}{*}{ GP/3T 2434aA } & \multirow{9}{*}{160} & A-B & 14,5 & 10,4 & $1: 0,71$ & 11 & \multirow{9}{*}{$6-7$} & & \multirow{9}{*}{ G } \\
\hline & & $B-C$ & 18 & 10,5 & $1: 0,58$ & 13 & & 1410 & \\
\hline & & C-D & 19 & 11,7 & 1:0,61 & 15 & & $1,4-1,9$ & \\
\hline & & $D-E$ & 20 & 13 & $1: 0,65$ & 14 & & & \\
\hline & & $\mathrm{E}-\mathrm{F}$ & 21,6 & 13 & $1: 0,60$ & 13 & & & \\
\hline & & $F-G$ & 22 & 15 & $1: 0,75$ & 15 & & $1,5-2$ & \\
\hline & & G-H & 21 & 19,6 & $1: 0,93$ & +-13 & & & \\
\hline & & $\mathrm{H}-\mathrm{I}$ & 19 & 22 & $1: 1,15$ & +-13 & & $1,5-2,5$ & \\
\hline & & $\mathrm{I}-\mathrm{J}$ & 19 & 26 & $1: 1,36$ & +-10 & & & \\
\hline \multirow{10}{*}{ GP/3T 2434aB } & \multirow{10}{*}{245} & $A-B$ & 9,5 & 7,7 & & 6 & \multirow{10}{*}{$8-9$} & & \multirow{10}{*}{$\begin{array}{l}A \\
B \\
C\end{array}$} \\
\hline & & $B-C$ & 10,5 & 8 & 1:0,81 & 8 & & & \\
\hline & & C-D & 11,8 & 16,7 & $1: 0,76$ & 8 & & & \\
\hline & & $D-E$ & 13 & 22 & $1: 1,41$ & 9 & & 1,6 & \\
\hline & & $\mathrm{E}-\mathrm{F}$ & 14,8 & 25,5 & $1: 1,69$ & 10 & & 1,1 & \\
\hline & & F-G & 15,5 & 26 & $1: 1,72$ & 11 & & & \\
\hline & & G-H & 16,4 & 26 & $1: 1,67$ & 11 & & 1,3 & \\
\hline & & $\mathrm{H}-\mathrm{I}$ & 18 & 27,2 & $1: 1,58$ & - & & & \\
\hline & & I-J & INC & 31 & $1: 1,51$ & 13 & & 1,2 & \\
\hline & & $\mathrm{J}-\mathrm{L}$ & INC & 28,6 & & 10 & & & \\
\hline \multirow{4}{*}{ GP/3T 2434aC } & \multirow{4}{*}{190} & $A-B$ & 25 & $36 ?$ & $1: 1,44$ & INC & \multirow{4}{*}{$6-7$} & & \multirow{4}{*}{-} \\
\hline & & $B-C$ & 25 & $36 ?$ & $1: 1,44$ & INC & & 1,9 & \\
\hline & & C-D & 29 & 31,6 & $1: 1,06$ & 17 & & $\begin{array}{l}1,4 \\
1,8\end{array}$ & \\
\hline & & D-E & 35 & 36,2 & $1: 1,03$ & 27 & & & \\
\hline \multirow{3}{*}{ GP/3T 2434aD } & \multirow{3}{*}{145} & $A-B$ & 19,8 & 34 & $1: 1,71$ & 16 & \multirow{3}{*}{$7-8$} & & \multirow{3}{*}{-} \\
\hline & & $B-C$ & 19 & 34 & $1: 1,78$ & 15 & & $\begin{array}{l}1,9 \\
1,7\end{array}$ & \\
\hline & & C-D & 22,5 & 34 & $1: 1,51$ & 16 & & & \\
\hline \multirow{5}{*}{ GP/3T 2434bcA } & \multirow{5}{*}{230} & $A-B$ & 28,6 & 36,2 & $1: 1,26$ & 17 & \multirow{5}{*}{6} & \multirow{5}{*}{1,9} & \multirow{5}{*}{-} \\
\hline & & $B-C$ & 29,3 & 36,5 & $1: 1,24$ & 16 & & & \\
\hline & & C-D & 28,5 & 36,7 & $1: 1,28$ & 18 & & & \\
\hline & & D-E & 28 & 37,9 & $1: 1,35$ & 16 & & & \\
\hline & & $E-F$ & 28,2 & 39,3 & $1: 1,39$ & 14 & & & \\
\hline
\end{tabular}




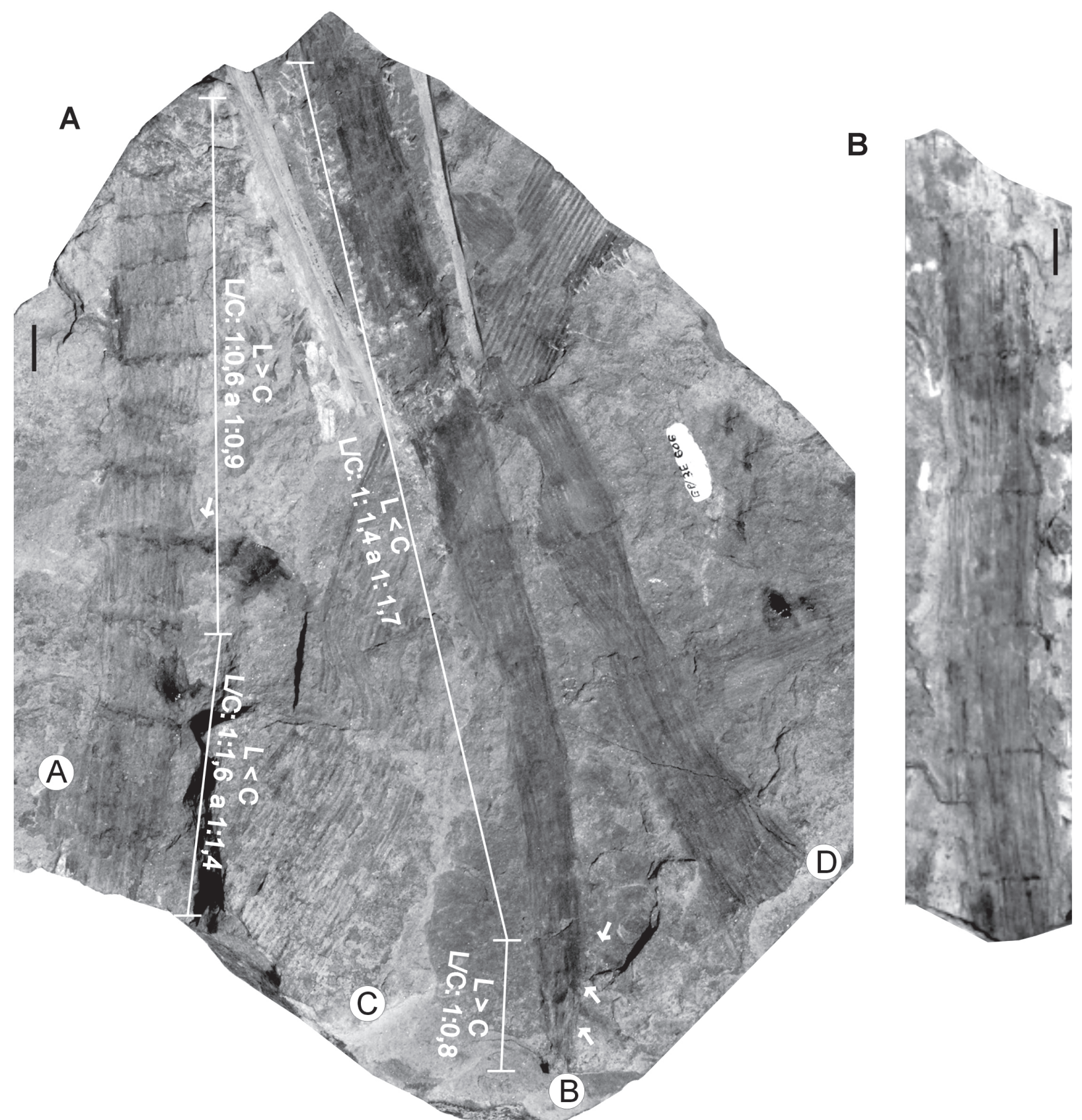

Figura 3. Paracalamites australis: A, GP/3T 2434a, os espécimes A e B representam porções mais apicais de caules, com grande variação na razão largura/comprimento $(L / C)$ dos entrenós; os espécimes $C$ e $D$ correspondem a porções basais de caules principais sem grande variação nesta relação. As setas indicam os ramos secundários que partem das regiões nodais mais apicais do espécime B; B, GP/ $3 \mathrm{~T} 2434 \mathrm{bH}$ corresponde a um caule principal. Escalas $=10 \mathrm{~mm}$.

Figure 3. Paracalamites australis: A, GP/3T 2434a, specimens A and B correspond to the distal parts of main stems, with high variation among the width/length ratios (L/C) of the internodes through these stems; specimens $C$ and $D$ correspond to proximal parts of main stems, showing discrete variation in these ratios. Arrows indicate the position of the secondary branches attached in the distal nodes of the specimen B; B, GP/3T $2434 \mathrm{bH}$ corresponds to a main stem. Scale bars $=10 \mathrm{~mm}$.

constantes através dos nós. Quando há mudança no número de costelas de um entrenó para outro, esta corresponde a dicotomias e recombinações dos feixes vasculares que ocorrem na passagem destes através da região nodal. No espécime GP/3T 2434a A, da sétima região nodal preservada parte um ramo em ângulo de $90^{\circ}$, constrito na base, com comprimento maior que 23,2 $\mathrm{mm}$ e $9 \mathrm{~mm}$ de largura (Figura $3 \mathrm{~A}$, espécime A). Este pequeno ramo apresenta duas regiões nodais, onde os entrenós apresentam cerca de $10 \mathrm{~mm}$ de comprimento. Nas três regiões nodais mais apicais do espécime GP/3T 2434aA, onde os nós ocorrem mais próximos uns dos outros, partem ramos (1, 2 e 3 ) em um ângulo de aproximadamente $60^{\circ}$, com comprimento superior a $15 \mathrm{~mm}$ e largura de 1,9 a 2,6 mm (Figura 3A, espécime B). Estes ramos apresentam os entrenós em torno de 3,5 $\mathrm{mm}$ de comprimento e algumas regiões nodais com possíveis verticilos foliares atados.

Discussão. O material aqui estudado pode ser incluído em 
Paracalamites australis, que foi um táxon criado para incluir caules articulados com nós e entrenós, sem conexão com ramos foliares ou partes reprodutivas, nos quais as costelas são opostas na região nodal e os entrenós apresentam comprimento maior que a largura. Os espécimes aqui analisados, além destas características diagnósticas citadas, mostram também, nos caules principais, as dimensões dos entrenós (comprimento e largura), o número de costelas e a distância entre elas muito semelhantes aos encontrados no material tipo, como descrito originalmente por Rigby (1966). Os caules das porções mais apicais (GP/3T 2434aA, B) apresentam, nas regiões proximais, o comprimento dos entrenós maior que suas larguras, o que corresponde à diagnose de $P$. australis. No entanto, nestes mesmos espécimes, o comprimento dos entrenós é menor do que suas larguras nas regiões mais distais. Segundo Rigby (1966), o que diferencia $P$. australis de $P$. levis é que esta última apresenta costelas mais finas e delicadas, e entrenós com comprimentos menores que as larguras. Sendo assim, em relação ao comprimento e a largura do entrenó, a porção proximal de um único espécime $(\mathrm{GP} / 3 \mathrm{~T} 2434 \mathrm{aA}, \mathrm{B})$ pode corresponder à diagnose de $P$. australis enquanto que a porção distal encaixase na de $P$. levis (Figura 3A, espécimes A, B). Zampirolli \& Bernardes-de-Oliveira (2000) também propuseram que a relação entre largura e comprimento dos entrenós é uma característica diagnóstica entre as espécies de Paracalamites já descritas no Brasil: P. australis (1:2 ou >2), P. montemorensis (1:1-1:1,99) e $P$. levis $(1: 0,99$ ou $<0,99)$. Porém, os espécimes aqui analisados contradizem a utilização desta relação morfométrica como uma feição de valor taxonômico. Nos caules principais (GP/3T $2434 \mathrm{aC}$, D e GP/3T 2434bH), por exemplo, a razão largura/ comprimento oscila entre $1: 1$ e 1:1,8, sugerindo tratar-se de $P$. montemorensis. Já nos caules das porções mais apicais, esta proporção se mantém entre $1: 1,2$ e 1:1,7, nas regiões mais proximais até as regiões nodais com ramificações, e entre 1:0,6 e 1:0,9, nas extremidades mais distais. Deste modo, os espécimes A e C de GP/3T 2434a, seriam incluidos em $P$. montemorensis pelos valores nas regiões proximais e em $P$. levis pelos das regiões mais distais (Figura 3A, B). Por sua vez, Rohn \& Rösler (1986), McLoughlin (1992) e Ronh \& Lages (2000) já haviam desconsiderado o valor taxonômico e/ou diagnóstico da relação largura/comprimento dos entrenós para espécies de Paracalamites, citando, neste sentido, somente $P$. australis como espécie válida para o gênero no Gondwana. Desta forma, o material aqui estudado é também classificado apenas em $P$. australis.

\section{Família PHYLLOTHECACEAE Gênero Phyllotheca Brongniart, 1828}

\section{Phyllotheca australis}

Material estudado. GP/3T 2434b (Figura 4D), GP/3T 2434d (Figura 4A), GP/3T 2435a, GP/3T 2435b (Figura 4C), GP/3T 2436a (Figura 4B), GP/3T 2436b.

Localidade. Afloramento Clube Caça e Tiro (Rocha-Campos, 1964; Boardman, 2006), próximo à margem esquerda do rio Taió, município de Taió, Santa Catarina, Brasil.
Descrição. O material analisado consiste de impressões de um caule articulado com ramos foliares que partem das regiões nodais, quatro ramos foliares isolados e sete verticilos (rosetas) foliares desconectados (Tabela 2). O espécime GP/ $3 \mathrm{~T} 2434 \mathrm{~d}$ representa um fragmento de caule com $98 \mathrm{~mm}$ de comprimento e largura variando entre 12,5-16,9 mm, com costelas e sulcos (feixes vasculares) finos e pouco nítidos que ultrapassam a linha nodal de forma oposta e variam de 14 a 17 costelas ao longo do caule (Figura 4A). Neste espécime estão presentes quatro regiões nodais, das quais partem ramos com folhas ( 2 ou 3 ramos visíveis por nó) em ângulos de $50^{\circ}-65^{\circ}$. Os entrenós, com $23 \mathrm{~mm}$ decomprimento médio, e largura entre $12,5-14 \mathrm{~mm}$, mostram a razão largura/ comprimento de $1: 1,7$ a $1: 1,9$. Os caules dos ramos secundários apresentam-se cobertos pelos verticilos foliares distantes entre si cerca de 4 a $8,9 \mathrm{~mm}$. Estes verticilos foliares têm os folíolos fusionados desde a base, formando bainhas em forma de funil que se abrem em ângulos de $25^{\circ}-35^{\circ} \mathrm{em}$ relação ao caule (Figura 4A). Neste espécime, a parte livre dos folíolos apresenta-se incompleta.

A amostra GP/3T 2435 apresenta quatro ramos foliares (A-D). Os espécimes GP/3T 2435A, C e D, são semelhantes aos ramos secundários conectados ao caule na amostra GP/ $3 \mathrm{~T} 2434 \mathrm{~d}$, mas a parte livre dos folíolos está presente, assim como em GP/3T 2436a. Estes ramos apresentam os entrenós cobertos pelos verticilos foliares, distanciados entre si de 6,9-8,8 mm, indicando serem ramos mais apicais. Os verticilos foliares têm os folíolos fusionados na base, formando bainhas de formato afunilado (Figura 4B). Os folíolos são lanceolados, uninervados, com o ápice agudo a levemente arredondado $\mathrm{e}$ a largura na porção livre é menor que $1 \mathrm{~mm}$. No espécime GP/ $3 \mathrm{~T} 2435 \mathrm{~B}$ corresponde a um ramo mais proximal onde a bainha das rosetas mostra um ângulo mais aberto, deixando o caule visível (Figura 4C). Este caule apresenta largura de 1,8 mm e entrenós de $12 \mathrm{~mm}$ de comprimento, com finas estriações (prováveis costelas). No nó mais basal deste caule, devido ao ângulo mais amplo da bainha, é possível visualizar a roseta em planta, bastante completa, o que permite observar 11 folíolos e inferir a ocorrência de 13 a 14 folíolos por nó. Os folíolos são lanceolados, uninervados, com ápices agudos a levemente arredondados e de comprimento total de $10 \mathrm{~mm}$, sendo livres, em média, por $60 \%$ de sua extensão; a largura é de $1,2 \mathrm{~mm}$ na porção livre. A amostra GP/3T 2434bc apresenta sete rosetas desconectadas (A-G). O espécime GP/3T 2434bcA apresenta um verticilo completo com 16 folíolos, sendo que nos demais espécimes é possível inferir a mesma quantidade de folíolos, mesmo estando estes incompletos. Os folíolos possuem comprimento entre $6,2-10 \mathrm{~mm}$, sendo que por $45 \%$ da sua extensão, em média, apresentam-se fusionados, formando uma bainha na região proximal. A parte livre dos folíolos é plana, linear, com o comprimento variando entre 3,9-5,5 $\mathrm{mm}$ e a largura entre 1,3-1,7 $\mathrm{mm}$. Apresentam uma nervura principal da base ao ápice que é agudo a levemente arredondado, quando preservado (Figura 4B-D). No espécime GP/3T 2434bF observa-se na superfície dos folíolos, estrias dispostas transversalmente que partem da nervura central em um ângulo de $30^{\circ}-45^{\circ}$ (Figura 4D). 

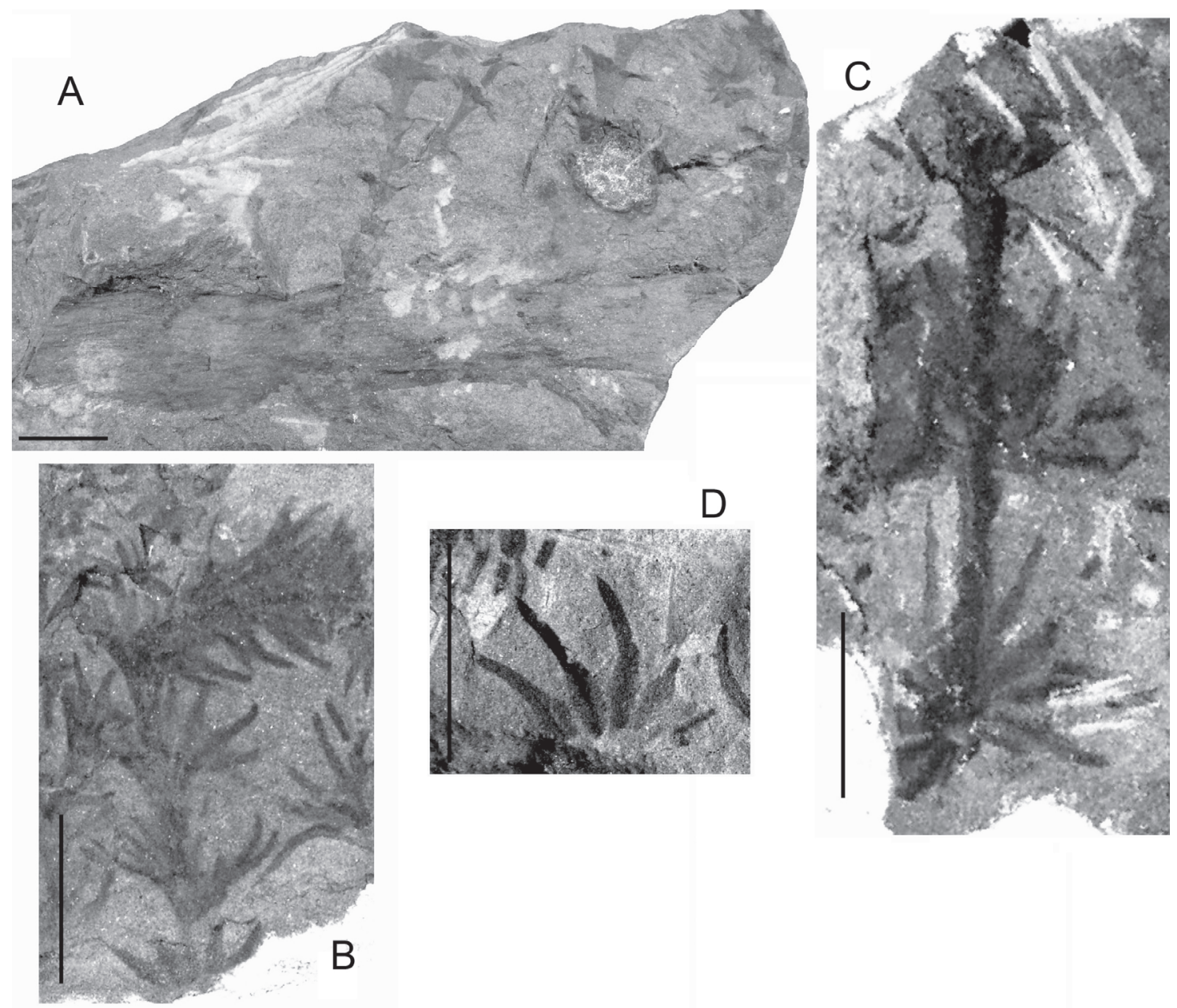

4. Phyllotheca australis: A, GP/3T 2434dA, caule principal com ramos foliares conectados; B, GP/3T 2436a, porção apical do ramo foliar; C, GP/3T 2435B, ramo foliar mais basal; D, GP/3T 2434bF, superfície de um verticilo foliar mostrando as estrias transversais que partem da nervura central de alguns folíolos. Escalas $=10 \mathrm{~mm}$.

Figure 4. Phyllotheca australis: A, GP/3T 2434dA, main stem bearing leaf shoots; B, GP/3T 2436a, distal portion of leaf shoots; C, GP/3T $2435 \mathrm{~B}$, proximal portion of the leaf shoot; D, GP/3T 2434bF, surface of a leaf whorl showing transversal shrinks arising from mid veins of some leaflets. Scale bars $=10 \mathrm{~mm}$.

Discussão. As espécies do gênero Phyllotheca encontradas no Gondwana são: P. griesbachi Zeiller (in Boureau, 1964), $P$. indica Bunbury (in Boureau, 1964) e P. australis Brongniart emend. Townrow (in Boureau, 1964). Os espécimes aqui descritos diferenciam-se de $P$. griesbachi por possuírem um número de folíolos por verticilo e o tamanho das bainhas nitidamente menores, além de bainhas que se mantêm relativamente mais próximas dos caules. As espécies mais similares às formas aqui descritas são $P$. indica e $P$. australis. Porém, muitos autores colocam $P$. indica em sinonímia à $P$. australis, que apresenta prioridade sobre a primeira (Boureau, 1964; Maheshwari, 1968; Mcloughlin, 1992; Rayner, 1992; Anderson \& Anderson, 1985, Rohn \& Lages, 2000). Segundo estes autores, as feições que distinguiriam $P$. indica de $P$. australis não teriam o valor taxonômico necessário para o estabelecimento de espécies distintas, a saber: divergência nos ângulos de abertura das bainhas (menores em $P$. australis); possível diferença no formato dos ápices dos folíolos (mais acentuadamente agudo em P. australis); distinção no grau de nitidez da nervura central dos folíolos.
Por outro lado, Rohn \& Lages (2000), ao aceitarem esta sinonimização, apresentam uma longa discussão, onde levantam muitos problemas taxonômicos relacionados às plantas do tipo Phyllotheca no Gondwana. Aquelas autoras colocam que as diferenças encontradas entre as espécies de Phyllotheca podem ser resultados da existência de uma grande variabilidade intra-específica, como ocorre em plantas modernas. Considerando-se os argumentos expostos nos trabalhos prévios, os presentes autores também aceitam Phyllotheca australis como a única espécie válida, com base no fato de que os caracteres mencionados como distintivos de cada espécie não são suficientemente precisos para serem utilizados em taxonomia. Em nossa opinião, eles podem variar acentuadamente entre os diferentes espécimes, seja devido a fatores tafonômicos, como no caso dos ângulos de abertura das bainhas e nitidez das nervuras medianas, seja devido à diferenciação intra-específica ou mesmo ontogenética, como em relação ao formato dos ápices foliares. Deste modo, não há como aceitá-los como feições diagnósticas em nível específico.

Os espécimes estudados apresentam o seguinte conjunto 
Tabela 2. Medidas (em mm) dos ramos foliares dos espécimes estudados. Abreviaturas: $\mathbf{C}=$ comprimento; $\mathbf{L}$, largura; $\mathbf{L} / \mathbf{C}$, razão largura/ comprimento; N, regiões nodais; $\mathbf{A}$, ângulos de inserção; Folíolos, 1 = comprimento total, 2 = comprimento da parte livre, 3 = largura na parte livre; INC, incompleto; t, total.

Table 2. Measurements (in $\mathrm{mm}$ ) of the leaf shoots of the studied specimens. Abbreviations: C, length; L, width; L/C, length/width ratio; $\mathbf{N}$, nodal regions; $\mathbf{A}$, angles of insertion; Folíolos (Leaflets), 1 = total length, 2, comprimento da parte livre, 3, width of the free part; INC, incomplete; $\mathbf{t}$, total.

\begin{tabular}{|c|c|c|c|c|c|c|c|c|c|c|c|c|}
\hline \multirow[t]{2}{*}{ Espécime } & \multirow{2}{*}{$\begin{array}{l}\text { C ramo } \\
\text { foliar }\end{array}$} & \multicolumn{3}{|c|}{ Entrenó } & \multicolumn{2}{|c|}{ Ramos foliares } & \multirow{2}{*}{$\begin{array}{l}\text { Folíolos por } \\
\text { verticilo foliar }\end{array}$} & \multicolumn{3}{|c|}{ Folíolos } & \multirow{2}{*}{$\begin{array}{l}\text { Å saída dos } \\
\text { folíolos }\end{array}$} & \multirow{2}{*}{$\begin{array}{c}\text { Distância entre } \\
\text { verticilos } \\
\text { foliares }\end{array}$} \\
\hline & & L & C & L/C & $N$ & $\AA$ & & 1 & 2 & 3 & & \\
\hline GP/3T 2434d & 98 & $\begin{array}{c}14 \\
13,6 \\
12,5\end{array}$ & $\begin{array}{l}23,3 \\
23,9 \\
23,5\end{array}$ & $\begin{array}{l}1: 1,66 \\
1: 1,75 \\
1: 1,88\end{array}$ & $\begin{array}{l}\text { A } \\
B \\
\text { C }\end{array}$ & $\begin{array}{c}50^{\circ} \\
65^{\circ} \\
65^{\circ} / 50^{\circ}\end{array}$ & - & - & - & - & $25-35^{\circ}$ & $4-8,9$ \\
\hline GP/3T 2435abA & 50 & & - & & - & & $\begin{array}{c}6-8 \\
(\mathrm{t}: 16)\end{array}$ & $\begin{array}{l}7,7 \\
8,8 \\
8,5 \\
8,3\end{array}$ & $\begin{array}{l}3,2 \\
3,6 \\
3,3 \\
3,5\end{array}$ & $\begin{array}{l}<1 \\
<1 \\
<1 \\
<1\end{array}$ & $25^{\circ}$ & $6,9-8,3$ \\
\hline GP/3T 2435abB & 34 & & 12,2 & & - & & $\begin{array}{c}11 \\
\text { (t: 14-16) }\end{array}$ & $\begin{array}{c}11 \\
10,1 \\
10,4 \\
7,8\end{array}$ & $\begin{array}{l}6,2 \\
4,6 \\
5,8 \\
3,4\end{array}$ & $\begin{array}{l}1,2 \\
1,1 \\
1,2 \\
1,2 \\
\end{array}$ & $80-90^{\circ}$ & 12,2 \\
\hline GP/3T 2435abC & 44 & & - & & - & & - & - & - & - & $25-35^{\circ}$ & $8,1-8,8$ \\
\hline GP/3T 2435abD & 43 & & - & & - & & $\begin{array}{l}5-6 \\
\text { (INC) }\end{array}$ & $\begin{array}{l}14,6 \\
18,6 \\
14,4 \\
13,8\end{array}$ & $\begin{array}{c}5 \\
7,5 \\
7,1 \\
6,8 \\
\end{array}$ & $\begin{array}{lll} & ? & 1 \\
? & 1 \\
? & 1 \\
? & 1\end{array}$ & $25-35^{\circ}$ & $7,9-9$ \\
\hline GP/3T 2436aA & 31 & & & & & & $6-9$ & $\begin{array}{l}11 \\
12 \\
\end{array}$ & $\begin{array}{l}3,6 \\
\text { INC }\end{array}$ & $? 1$ & $30^{\circ}$ & $5-8,8$ \\
\hline $\begin{array}{l}\text { GP/3T 2434bcA } \\
\text { Roseta completa }\end{array}$ & - & & - & & & - & $\mathrm{t}: 16$ & $\begin{array}{c}6,6 \\
6,7 \\
6,2 \\
7 \\
7,6 \\
7,7 \\
6,8 \\
7,6\end{array}$ & $\begin{array}{c}3,9 \\
4,5 \\
4 \\
4,2 \\
4,7 \\
4,3 \\
2,9 \\
3,8\end{array}$ & $\begin{array}{l}1,3 \\
1,4 \\
1,3 \\
1,4 \\
1,4 \\
1,4 \\
1,3 \\
1,3\end{array}$ & - & - \\
\hline GP/3T 2434bcB & - & & - & & & - & $\begin{array}{c}13 \\
(\mathrm{t}: ? 16)\end{array}$ & $\begin{array}{c}10 \\
9 \\
8,9 \\
8,5 \\
8,8 \\
7,4 \\
7,8 \\
7,5 \\
\end{array}$ & $\begin{array}{c}5,3 \\
4 \\
4,5 \\
4,5 \\
5,5 \\
4,7 \\
3,9 \\
3,8 \\
\end{array}$ & $\begin{array}{l}1,6 \\
1,5 \\
1,7 \\
1,5 \\
1,3 \\
1,6 \\
1,7 \\
1,3 \\
\end{array}$ & - & - \\
\hline GP/3T 2434bC & - & & - & & & - & $\begin{array}{c}13 \\
\text { (t: 16-18) }\end{array}$ & $\begin{array}{l}5,9 \\
5,4 \\
5,7 \\
6,3 \\
6,3 \\
7,3 \\
7,9\end{array}$ & $\begin{array}{c}3,5 \\
4,3 \\
3,6 \\
5,5 \\
5 \\
4,3 \\
4,7\end{array}$ & $\begin{array}{l}1,1 \\
1,1 \\
0,9 \\
1,2 \\
1,4 \\
1,1 \\
0,9\end{array}$ & - & - \\
\hline GP/3T 2434bD & - & & - & & - & & 7 & $\begin{array}{c}11,7 \\
12,9 \\
13 \\
10,2 \\
11,3 \\
11,6 \\
10,6\end{array}$ & $\begin{array}{l}4,3 \\
6,5 \\
7,1 \\
6,4 \\
6,2 \\
6,8 \\
4,8\end{array}$ & $\begin{array}{l}1,2 \\
1,5 \\
1,4 \\
0,9 \\
1,5 \\
1,4 \\
1,2\end{array}$ & - & - \\
\hline GP/3T 2434bF & - & & - & & - & & 3 & INC & INC & $\begin{array}{l}1,5 \\
1,6 \\
1,6\end{array}$ & - & - \\
\hline
\end{tabular}


de características que permitem enquadrá-los em $P$. australis: (i) folíolos uninervados inseridos ao redor da região nodal; (ii) fusionamento dos folíolos desde a base até cerca de $40 \%$ do comprimento, formando bainhas em forma de funil que cobrem parcial ou totalmente os entrenós; (iii) dimensões e formato dos folíolos compatíveis com os de P. australis. Apenas o número de folíolos por verticilo foliar, cerca de 16, diferencia-se levemente da diagnose original de $P$. australis que apresenta de 18 a 23 folíolos por verticilo. No entanto, espécimes com número de folíolos similar, descritos por Rohn \& Lages (2000) para distintos sítios de Cerquilho, em São Paulo, foram também incluídos em $P$. australis por aquelas autoras. De fato, na opinião dos presentes autores, um número ligeiramente inferior de folíolos não é, em si, um caráter diagnóstico significativo a ponto de refutar a classificação do presente material em $P$. australis ou de justificar a proposição de um novo táxon. Por fim, este material apresenta uma série de estrias transversalmente dispostas na superfície dos folíolos, feição idêntica a que foi relatada por Rohn \& Lages (2000) no material de Cerquilho, classificado por elas como P. australis. Desta forma, o material aqui estudado é classificado em $P$. australis.

\section{CONSIDERAÇÕES FINAIS}

Em termos bioestratigráficos, formas de Phyllotheca e Paracalamites são comuns em depósitos permianos da bacia do Paraná e ocorrem em várias unidades. Restos de caules atribuíveis a Paracalamites distribuem-se no Permiano, ao longo da bacia, estando aparentemente ausentes apenas nas formações Palermo e Irati (Rocha-Campos \& Rösler, 1978; Rohn \& Rösler, 2000). Já a espécie P. australis parece ser comum apenas em unidades de idade eopermiana, quais sejam, Subgrupo Itararé e Formação Rio Bonito. Ramos foliares de esfenófitas do tipo Phyllotheca são registrados em abundância em estratos que vão do topo do Subgrupo Itararé até o topo da Formação Rio Bonito, sendo, portanto, restritas ao Eopermiano (Sakmariano-Artinskiano) (RochaCampos \& Rösler, 1978; Iannuzzi \& Souza, 2005). Nas demais áreas do Gondwana uma distribuição semelhante destes táxons se repete, exceto pelo fato de que formas de Phyllotheca podem ocorrer até o início do Neopermiano da Austrália (Retallack, 1980).

Deste modo, estas formas são por demais longevas para auxiliar na determinação de uma idade mais precisa do que a Artinskiana, estabelecida anteriormente pelos invertebrados marinhos para os pacotes da porção média da Formação Rio Bonito na região de Taió. Por outro lado, elas são ótimas para indicar a presença de ambientes mais continentais, uma vez que os restos analisados, por apresentarem caules e ramos foliares bem preservados e parcialmente conectados entre si, denotam pouco transporte do material vegetal. Sendo assim, pode-se inferir a ocorrência de depósitos, no mínimo, transicionais posicionados estratigraficamente abaixo dos níveis de origem marinha que contêm os invertebrados da "Assembléia de Taió". Na realidade, os achados reportados por Boardman (2006) e Boardman et al. (2005, 2006) já apontam para existência de ambientes transicionais na área de Taió. Isto implica em assumir a ocorrência de depósitos representativos de ambientes costeiros em uma área geologicamente reconhecida por seus depósitos marinhos, considerados como pertencente ao Membro Paraguaçu. O posicionamento estabelecido por Rocha-Campos (1964) dos restos vegetais na porção basal da Formação Rio Bonito, abaixo dos níveis contendo a fauna conchífera, pode indicar a existência de depósitos relativos ao Membro Triunfo nas exposições examinadas. Esta unidade basal da Formação Rio Bonito é considerada de origem continental e tem sido associada aos depósitos de carvão gerados no estado do Paraná. Sua presença na área de Taió pode ter sido subestimada anteriormente devido a pouca espessura e rara ocorrência de depósitos contendo restos vegetais nas seções aflorantes da região. Realmente, a partir da região norte de Santa Catarina, em direção ao sul e a oeste da bacia, o Membro Triunfo se torna pouco espesso dentro das seções correspondentes ao Rio Bonito, sendo representado apenas por conglomerados basais de origem fluvial. A possibilidade de esta unidade estar presente na área analisada deve ser levada em consideração em futuros estudos que versem sobre a estratigrafia desta porção da bacia.

Por fim, deve-se destacar que os espécimes estudados permitem questionar a proposta de Zampirolli \& Bernardesde-Oliveira (2000) de utilização de relações entre comprimento e largura dos entrenós como uma feição diagnóstica em nível específico para formas de Paracalamites. Isto porque se constatou claramente, em diferentes espécimes, a ocorrência de distintas razões largura/comprimento ao longo de um mesmo caule. Conclui-se, portanto, que tal feição pode não ter validade taxonômica, devendo ser reavaliada a sua utilização como um caráter diagnóstico em trabalhos futuros.

\section{AGRADECIMENTOS}

Os autores agradecem a L. F. Lopez (UFRGS) pela produção do material fotográfico e a C. H. Nowatzki, pela colaboração nos trabalhos de campo e descrição do perfil. Esta pesquisa foi financiada pelo CNPq na forma de bolsa de pesquisa (RI, PQ 304655/2004-0) e de fomento para projeto (474153/2004-5), e pela FAPERGS na forma de fomento para projeto (PROAPP 04/1066-0). Esta é uma contribuição do projeto "Estudos paleontológicos integrados e de alta resolução em áreas da porção central da Bacia do Paraná, Taió, SC" do Laboratório de História da Vida e da Terra da UNISINOS e do Centro de Investigação do Gondwana da UFRGS ao Projeto IGCP 471.

\section{REFERÊNCIAS}

Anderson, J.M. \& Anderson, H.M. 1985. Paleoflora of Southern Africa. Prodromus of South African Megafloras, Devonian to Lower Cretaceous. $1^{\mathrm{a}}$ ed. Rotterdam, A.A. Balkema, 423 p.

Bernardes-de-Oliveira, M.E.C. 1969. Flora da Formação Rio Bonito: Glossopteris, Noeggerathiopsis, Sphenopteris, Gangamopteris e Rhabdotaenia, na subida do Bainha, Criciúma, Santa Catarina. Faculdade de Filosofia, Ciências e Letras, Uni- 
versidade de São Paulo, Dissertação de Mestrado, 51 p.

Bernardes-de-Oliveira, M.E.C. 1977. Tafoflora eogonduânica da Camada Irapuã, Formação Rio Bonito (Grupo Tubarão), SC. Instituto de Geociências, Universidade de São Paulo, Tese de Doutorado, $301 \mathrm{p}$.

Bernardes-de-Oliveira, M.E.C. 1978. Frutificações de pteridospermófitas eogondvânicas da Camada Irapuá, Formação Rio Bonito, nos arredores de Criciúma, SC. In: CONGRESSO BRASILEIRO DE GEOLOGIA, 30, 1978. Anais, Recife, SBG, 2:986-1001.

Bernardes-de-Oliveira, M.E.C. 1980. Tafoflora eogondvânica da Formação Rio Bonito (Camada Irapuá), Bacia do Paraná, Brasil. In: CONGRESO LATINOAMERICANO DE PALEONTOLOGÍA, 1, 1980. Actas, Buenos Aires, APA, 6:69-88.

Bernardes-de-Oliveira, M.E.C. 1988. Equisetales eogondvânicas da Tafoflora Irapuá, Formação Rio Bonito (Permiano Inferior). Anais da Academia Brasileira de Ciências, 60:45-60.

Bernardes-de-Oliveira, M.E.C. \& Carvalho, R.G. 1981. Frutificações femininas de glossopteridófitas da Formação Rio Bonito, Grupo Tubarão, estado de Santa Catarina, Brasil. In: CONGRESSO LATINOAMERICANO DE PALEONTOLOGÍA, 2, 1981. Anais, Porto Alegre, UFRGS, 1:181-199.

Beurlen, K. 1954. Análise paleogeográfica da Série Tubarão e possibilidades de novas bacias carboniferas. Rio de Janeiro, Departamento Nacional da Produção Mineral, Divisão de Geologia e Mineralogia, 10 p. (Notas Preliminares e Estudos 74).

Beurlen, K. 1957. Das Gondwana-Inlandeis in Südbrasilien. International Journal of Earth Sciences, 45(3):595-599.

Boardman, D.R. 2006. Tafoflora de Taió, Santa Catarina (Permiano Inferior, Formação Rio Bonito, Bacia do Paraná). Instituto de Geociências, Universidade Federal do Rio Grande do Sul, Dissertação de Mestrado, 112 p.

Boardman, D.R.; Iannuzzi, R.; Dutra, T.L.; Nowatski, C.H. \& De Lima, L. 2005. Macroflora do município de Taió, SC (Paleozóico Superior, Bacia do Paraná). In: CONGRESSO BRASILEIRO DE PALEONTOLOGIA, 19, 2005. Resumos, Aracajú, UFS, CD.

Boardman, D.R.; Iannuzzi, R.; Dutra, T.L. 2006. Tafoflora de Taió, SC (Permiano Inferior, Formação Rio Bonito, Bacia do Paraná. In: SEMANA ACADÊMICA DOS ALUNOS DE PÓS-GRADUAÇÃO EM GEOCIÊNCIAS, 1, 2006. Resumos expandidos, Porto Alegre, UFRGS, p. 27-30.

Bortoluzzi, C.A. 1975. Étude de Quelques Empreintes de La Flore Gondwanienne du Brésil. In: CONGRÈS NATIONAL DES SOCIÉTÉS SAVANTES, 95, 1970. Actes, Paris, 3:171-187.

Boureau, E. 1964. Traité de Paléobotanique: Sphenophyta. Paris, Masson et Cie, v. 3, 554 p.

Dickins, J.M. 1963. Permian pelecypods and gastropods from Western Australia. Bulletin of Bureau of Mineral Resources, Geology and Geophysics of Australia, 41:1-58.

Dolianiti, E. 1946. Noticias sobre novas formas na Flora de Glossopteris do Brasil meridional. Rio de Janeiro, Departamento Nacional da Produção Mineral, Divisão de Geologia e Mineralogia, 6 p. (Notas Preliminares e Estudos 34).

Dolianiti, E. 1948. A Paleobotânica no Brasil. Rio de Janeiro, Departamento Nacional da Produção Mineral, Divisão de Geologia e Mineralogia, 87 p. (Boletim 123).

Dolianiti, E. 1953a. A Flora do Gondwana Inferior em Santa Catarina. I-O Gênero Glossopteris. Rio de Janeiro, Departamento Nacional da Produção Mineral, Divisão de Geologia e Mineralogia, 7 p. (Notas Preliminares e Estudos 60).
Dolianiti, E. 1953b. A Flora do Gondwana Inferior em Santa Catarina. II - O Gênero Taeniopteris. Rio de Janeiro, Departamento Nacional da Produção Mineral, Divisão de Geologia e Mineralogia, 7 p. (Notas Preliminares e Estudos 61).

Dolianiti, E. 1953c. A Flora do Gondwana Inferior em Santa Catarina. III - O Gênero Actinopteris. Rio de Janeiro, Departamento Nacional da Produção Mineral, Divisão de Geologia e Mineralogia, 3 p. (Notas Preliminares e Estudos 62).

Dolianiti, E. 1954a. A Flora do Gondwana Inferior em Santa Catarina. IV-O Gênero Vertebraria. Rio de Janeiro, Departamento Nacional da Produção Mineral, Divisão de Geologia e Mineralogia, 5 p. (Notas Preliminares e Estudos 81).

Dolianiti, E. 1954b. A Flora do Gondwana Inferior em Santa Catarina. V - O Gênero Gangamopteris. Rio de Janeiro, Departamento Nacional da Produção Mineral, Divisão de Geologia e Mineralogia, 12 p. (Notas Preliminares e Estudos 89).

Dolianiti, E. 1956a. Um verticilo de Glossopteris no Gondwana do estado de Santa Catarina. Anais da Academia Brasileira de Ciências, 28(1):115-118.

Dolianiti, E. 1956b. A Flora do Gondwana Inferior em Santa Catarina. VI-O Gênero Sphenopteris. Rio de Janeiro, Departamento Nacional da Produção Mineral, Divisão de Geologia e Mineralogia, 8 p. (Notas Preliminares e Estudos 95).

Iannuzzi, R. \& Souza, P.A. 2005. Floral succession in the Lower Permian deposits of the Brazilian Paraná Basin: an up-to-date overview. In: S.G. Lucas \& K.E. Zigler (eds.) The Nonmarine Permian. New Mexico Museum of Natural History and Science, Bulletin n. 30, p. 144-149.

Kegel, W. \& Costa, M.T. 1951. Espécies neo-paleozóicas do Brasil, da família Aviculopectenidae, ornamentadas com costelas fasciculadas. Rio de Janeiro, Departamento Nacional da Produção Mineral, Divisão de Geologia e Mineralogia, 61 p. (Boletim 137).

Krebs, A.S.J. \& Menezes Filho, N.R. 1984. Projeto mapeamento geológico para carvão, área de Taió - Rio do Sul, SC. Rio de Janeiro, Departamento Nacional da Produção Mineral, Divisão de Geologia e Minaralogia, 154 p. (Relatório Final).

Maheshwari, H.K. 1968. Studies in the Glossopteris Flora of India. Remarks on Tryzygia speciosa noyle with reference to the Genus Sphenophyllum Koenig. Palaeobotanist, 16:83-287.

McLoughlin, S. 1992. Permian Sphenophytes from the Collies and Perth Basins, Western Austrália. Review of Palaeobotany and Palynology, 75:153-182.

Millan, J.H. 1977. Moldes medulares da tafoflora gondwânica de Monte Mor, Estado de São Paulo. Anais da Academia Brasileira de Ciências, 49(1):195-204.

Oliveira, E. 1930. Fósseis marinhos da Série Itararé no Estado de Santa Catarina. Anais da Academia Brasileira de Ciências, 2:31-40.

Rayner, J.F. 1992. Phyllotheca: the pastures of the Late Permian. Palaeogeography, Palaeoclimatology, Palaeoecology, 92:31-40.

Read, C.B. 1941. Plantas fósseis do Neo-Paleozóico do Paraná e Santa Catarina. Rio de Janeiro, Departamento Nacional da Produção Mineral, Divisão de Geologia e Mineralogia, 102 p. (Monografia 12).

Reed, F.R.C. 1930. Uma nova fáunula Permo-Carbonifera do Brasil. Rio de Janeiro, Ministério da Agricultura, Divisão de Geologia e Mineralogia, 45 p. (Monografia 10).

Reed, F.R.C. 1935. A new brachiopod from the Upper Carboniferous of Santa Catarina. Anais da Academia Brasileira de Ciências, 7(2):113-122.

Retallack, G.J. 1980. Late Carboniferous to Middle Triassic megafossil floras from Sydney Basin. Bulletin of the Geological 
Survey of New South Wales, 26:384-430.

Rigby, J.F. 1966. The Lower Gondwana floras of the Perth and Collie basins, western Australia. Paleontographica Abt. B, 118(46):113-152.

Rigby, J.F. 1969. Permian Sphenopsida from Antarctica. Contributions to Paleontology. Descriptions and distribution of species of the fossil plants genera Phyllotheca, Schizoneura, Paracalamites and Umbellapyllites. Geological Survey Professional Paper, 613F:1-13.

Rigby, J.F. 1972a. The Notocalamitaceae, a new family of Upper Paleozoic Equisetaleans. Palaeobotanist, 19(2):161-163.

Rigby, J.F. 1972b. The upper Palaeozoic Flora at Lauro Müller, Santa Catarina, Southern Brazil. Anais da Academia Brasileira de Ciências, 44:281-293.

Rocha-Campos, A.C. 1964. Contribuição à estratigrafia da região de Taió, Santa Catarina. Instituto de Geociências, Universidade de São Paulo, Tese de Doutorado, 64 p.

Rocha-Campos, A.C. 1967. The Tubarão Group in the Brazilian portion of the Paraná Basin. In: J.J. Bigarella.; R.D. Becker \& I.D. Pinto (eds.) Problems in Brasilian Gondwana Geology, IG/UFPR, p. 27-102.

Rocha-Campos, A.C. 1970. Moluscos permianos da Formação Rio Bonito. Rio de Janeiro, Departamento Nacional da Produção Mineral, Divisão de Geologia e Mineralogia, 89 p. (Boletim 251).

Rocha-Campos, A.C. \& Rösler, O. 1978. Late Paleozoic faunal and floral sucessions in the Paraná Basin, Southeastern Brazil. Boletim do Instituto de Geologia da USP, 9:1-16.

Rocha-Campos, A.C. \& Simões, M. 1993. Australomya sinuosa sp. n., um novo megadesmídeo (Mollusca, Pelecypoda) da Formação Rio Bonito (Permiano), Bacia do Paraná, Brasil. Anais da Academia Brasileira de Ciências, 65(1):29-39.

Rohn, R. \& Lages, L.C. 2000. Lower Permian Sphenopsids from
Cerquilho, Northestern Paraná Basin, Brazil. Revue Paléobiologie, 19(2):359-379.

Rohn, R. \& Rösler, O. 1986. Caules de Sphenophyta da Formação Rio do Rasto (Bacia do Paraná, Permiano Superior). Boletim do Instituto de Geologia da USP, 17:39-56.

Rohn, R. \& Rösler, O. 2000. Middle to Upper Permian phytostratigraphy of the eastern Paraná Basin. Revista Universidade de Guarulhos, Geociências, 5(suplem.):69-73.

Runnegar, B. 1972. Late Paleozoic Bivalvia from South America: provincial affinites and age. Anais da Academia Brasileira de Ciências, 44(1):29-39.

Schneider, R.L.; Muhlmann, H.; Tommasi, E.; Medeiros, R.A.; Daemon, R.F. \& Nogueira, A.A. 1974. Revisão Estratigráfica da Bacia do Paraná. In: CONGRESSO BRASILEIRO DE GEOLOGIA, 28, 1974. Anais, Porto Alegre, UFRGS, 1:41-65.

Stewart, W.N. \& Rothwell, G.W. 1993. Paleobotany and the evolution of plants. $1^{\text {a }}$ ed. Cambridge, Cambridge University Press, $521 \mathrm{p}$.

White, J.C. 1908. Relatório final da Comissão de Estudos das Minas de Carvão de Pedra do Brasil. Rio de Janeiro, DNPM, 617 p. (ed. Fac-similar de 1988).

Zampirolli, A.P. \& Bernardes-de-Oliveira, M.E. 2000. O Gênero Paracalamites Zalessky, 1927 na tafoflora de Itapeva, Carbonífero Superior do Grupo Tubarão, sudoeste do estado de São Paulo, Brasil. Revista do Instituto Geológico, 21(1/2):7-15.

Received in May, 2007; accepted in September, 2007. 